\title{
Effects of mesenchymal stem cells on solid tumor metastasis in experimental cancer models: a systematic review and meta-analysis
}

Jing-Huan Li ${ }^{1,2,3 \dagger}$, Wen-Shuai Fan ${ }^{4 \dagger}$, Mi-Mi Wang ${ }^{1,2}$, Yan-Hong Wang ${ }^{1,2}$ and Zheng-Gang Ren ${ }^{1,2^{*}}$

\begin{abstract}
Background: It has been reported mesenchymal stem cells (MSCs) are recruited to and become integral parts of the tumor microenvironment. MSCs might have an active role in solid tumor progression, especially cancer metastasis. However, the contribution of MSCs in the process of cancer metastasis is still controversial. In this review, we performed a meta-analysis on the effects of MSCs administration on cancer metastasis based on published preclinical studies.

Methods: The PRISMA guidelines were used. A total of 42 publications met the inclusion criteria. Outcome data on the incidence and the number of cancer metastasis as well as study characteristics were extracted. Quality of the studies was assessed according to SYRCLE Risk of Bias tool. Random-effects meta-analysis was used to pool estimates.

Results: Of the 42 studies included, 32 reported that MSCs administration promoted outcome events (numbers or incidences of cancer metastasis), and 39 reported data suitable for meta-analysis. The median effect size (RR) was 2.04 for the incidence of cancer metastasis ( $95 \% \mathrm{Cl} 1.57-2.65, \mathrm{I}^{2}=21 \%$ ), and the median effect size (SMD) was 1.23 for the number of cancer metastasis $\left(95 \% \mathrm{Cl} 0.43-2.03, \mathrm{I}^{2}=89 \%\right)$. Heterogeneity was observed, with the greater impact based on study length and different ways of metastasis measurement and MSCs administration.

Conclusion: Our results suggested MSCs administration increased the number and the incidence of cancer metastasis in experimental cancer models. High heterogeneity and poor reported risk of bias limit the quality of these findings. Further preclinical studies with better design and adequate reporting are still needed.
\end{abstract}

Keywords: Neoplasm metastasis, Mesenchymal stem cells, Animal model, Meta-analysis

\section{Background}

Distant metastasis is a major feature of cancer cells, which is responsible for most cancer-associated mortality [1]. The biology of the cancer cells plays an important role in cancer metastasis. However, more and more evidence supports the role of cancer-associated stroma in cancer metastasis and poor clinical outcomes [2-4]. And therapeutic candidates that targeted stromal members are widely explored to improve outcomes of cancer treatment [3].

\footnotetext{
*Correspondence: ren.zhenggang@zs-hospital.sh.cn

†Jing-Huan Li and Wen-Shuai Fan contributed equally to this work

${ }^{2}$ Liver Cancer Institute, Zhongshan Hospital, Fudan University,

Shanghai 200032, China

Full list of author information is available at the end of the article
}

Mesenchymal stem cells (MSCs) have been successfully isolated from several primary solid tumors, such as ovarian cancer, breast cancer, gastric cancer, and osteosarcoma [5, 6], suggesting MSCs a critical part of cancer stroma. MSCs, also known as mesenchymal stromal cells, are a heterogeneous group of multi-potent progenitor cells that could contribute to maintenance and regeneration of a variety of tissues [6,7]. In the case of tissue injury or inflammatory, MSCs could be mobilized and recruited to the damage site upon sensing wound-associated signals [6]. Since cancer development is generally accompanied by multiple desmoplastic reactions, which confer the tumor site a 'wound that never heals' [8], MSCs has been reported to recruit to several cancer tissues, such as breast cancer [9], prostate cancer [10], and 
osteosarcoma [11]. And identified endocrine and paracrine signals, such as Sdf-1/CXCR4 and PGF/VEGFR1 axes [9], are found to be involved in this process. Therefore, previously studies mostly focused on the potential use of MSCs as vehicles for delivering anti-cancer agents. Till now, there are at least four clinical studies elucidating modulated-MSC-based therapy in patients with cancer but no solid results have yet been reported (ClinicalTrials.gov Identifier: NCT02008539, NCT02530047, NCT02068794, and NCT01983709).

However, MSCs could participate in tumor progression directly by influencing cancer cell biology or indirectly by modulating the immune status and angiogenic process, resulting the role MSCs played in tumor progression is complicated, especially in tumor metastasis [8]. Until recently, there are several studies focused on the effects of MSCs in tumor metastasis in animal models, but the results are conflicting. For example, Kaenoub et al. reported that MSCs within tumor stroma promote breast cancer metastasis [2], whereas Meleshina et al. found MSCs reduced metastasis of breast cancer [12]. Yan and his colleagues suggested opposite conclusion to $\mathrm{Li}$ and his colleagues' conclusion that MSCs inhibit hepatocarcinoma metastasis $[5,13]$. Moreover, to our knowledge, these relevant preclinical studies have never been systematically analyzed and strong evidence with animal model study is still lacking.

Therefore, in this review, we examine the current stateof-the-art of preclinical studies of the effect of MSCs administration on tumor metastasis, and we discuss their advantages, limitations and future potential.

\section{Methods}

\section{Search strategy and literature selection}

The PRISMA guidelines were used to conduct this review and meta-analysis [14]. Studies of MSCs administration in animal models of solid tumor metastasis were identified from PubMed, EMBASE, and Cochrane library from January 2000 to March 2017. The following search strategy was used for PubMed and EMBASE: ("mesenchymal stromal cell" OR "mesenchymal stem cell") AND (cancer OR tumor) AND (preclinical OR animal) AND (metastasis OR progression). The search strategy used for Cochrane library was (mesenchymal stromal cell OR mesenchymal stem cell) AND (cancer OR tumor). Secondary references were also reviewed. Studies met all following criteria were included: (1) the study assessed effects of MSCs administration on incidence or number of metastasis in animal models with experimental cancer, (2) the research was performed in animals in vivo, (3) the research was an original full-text literature with unique data, (4) the study had appropriate control groups. Studies were excluded if the MSCs used involved additional active components such as gene/drug modification, or the cancer model was hematological malignancies rather than solid tumor. All the publications were randomly allocated to three independent reviewers $(\mathrm{Li}, \mathrm{Fan}$, and Wang), who screened out candidate papers mainly based on title and abstract. Full articles of candidate papers were subsequently analyzed in detail. The flow diagram of search strategy and literature selection is shown in Fig. 1.

\section{Data extraction}

Data on animal model characteristics (animal species/ strain and gender), cancer model (cancer cell type and implantation route), MSCs administration characteristics (MSCs origin, source, identification test, as well as administration route, dose, and timing related to cancer implantation), and primary outcome measures (region of metastasis, number or incidence of metastasis, and conclusion) were extracted. We also extracted bibliographic data, including authors, year of publication, and country or region.

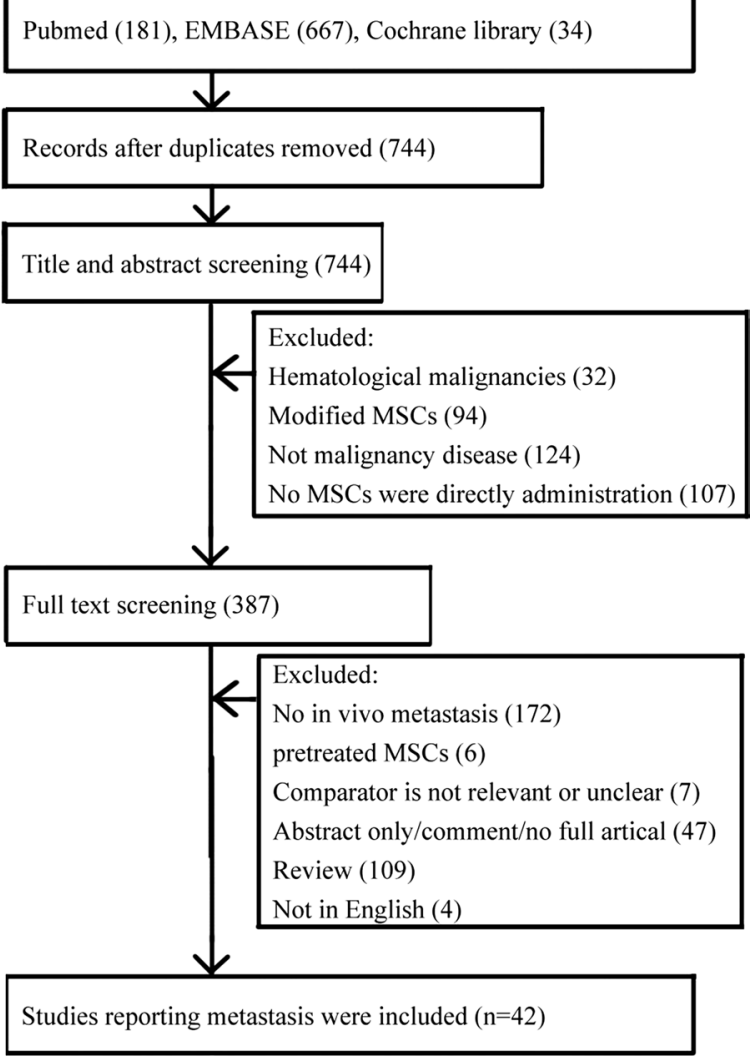

Fig. 1 Flow diagram of the current meta-analysis. Studies of MSCs administration in animal models of solid tumor metastasis were identified from PubMed, EMBASE, and Cochrane library until March 2017. A total of 42 publications met the inclusion criteria 
For included 42 literatures, all independent comparisons of metastasis in animals with experimental cancer having MSCs or blank control treatment were identified. Replications were also collected separately. Information on primary outcome were extracted from both text and graphs, when raw data or mean/median/incidence, SD/ $\mathrm{SE}$ were reported or recalculated. ImagePro Plus v6.0 software was used to obtain values from graphs. When the number of animals was reported as a range, the lowest group size was collected. When no clear data could be extracted, the report was excluded from further meta-analysis.

\section{Assessment of study quality and risk of bias}

Quality and risk of bias was assessed by SYRCLE Risk of Bias tool [15]. When the number of animal per group reported in the Method section equaled to the number mentioned in the Results section or figure legends, we assumed there had no exclusion of animals. All the studies were reviewed independently by two reviewers.

Besides, to overcome the fact that there were too many items as "unclear" because of the poor description of details on experiment design and methods, we included 3 items in other Bias: (1) inappropriate influence of funders, (2) mention of randomization at any level, and (3) mention of blinding at any level. For inappropriate influence of funders, "Yes" indicated non-industry source of funding, no funding, or no conflict of interest, "No" indicated the study was funded by industry or author mentioned conflict of interests, "unclear" indicated funding source or conflict of interest was not mentioned. For mention of randomization or blinding, "Yes" indicated reported and "No" indicated unreported.

\section{Statistical analyses}

Data were analyzed using Review Manager Software (RevMan, version 5.2). For the measurement of outcome event "number of metastases", the standardized mean difference (SMD) was computed using mean and SD. If the data were shown as median and percentiles, the data were converted to mean and SD. For the measurement of outcome event "incidence of metastases", the risk ration (RR) was computed. When individual comparisons with zero events in one group, either control or treatment group, a continuity correction of 0.5 was added to each cell, as implemented in RevMan software.

Considering the anticipated heterogeneity, random effects models were used to conducted meta-analysis. Mean effect size, 95\% confidence intervals (95\% CI), significance, and forest plots were analyzed by the inversevariance method and the standard mean differences in RevMan software. The possibility of publication bias was assessed by visually evaluating the asymmetry in the funnel plots. Heterogeneity was examined by using $\mathrm{I}^{2}$.

Sensitivity analysis and subgroup analysis were performed to further assess the robustness of our findings and explain the observed heterogeneity

\section{Results}

Study selection process and study characteristics

As shown in Fig. 1, a total of 42 publications were identified. The detail characteristics of these studies were listed in Additional file 1: Table S1. Out of the 42 publications, 32 studies came with the conclusions that MSCs administration promoted outcome events (numbers or incidences of cancer metastasis) in animal studies. Excluded 3 publications that could not extract clear data, a total of 39 studies with 66 independent comparisons were included for further meta-analysis.

The characteristics of the included 39 publications with 66 independent comparisons were shown in Table 1. Breast cancer metastases were studies in $48.5 \%$ of the experiments. Metastases of osteosarcoma, hepatocellular carcinoma, colon cancer, and melanoma were studies in $12.1,9.1,6.1$, and $4.5 \%$ of the experiments, respectively. The most popular metastases region was lung (62.1\%), and the second was liver (10.6\%). The remaining of $27.3 \%$ experiments studied the metastases in bone, lymph node, skin, or whole body in general.

Out of the studies, most experiments (83.3\%) conducted in nude mice. Female and male animals were used in $53.0 \%$ and $18.2 \%$ of the studies. MSCs derived from human bone marrow were used in most experiments (45.5\%). Also, MSCs derived from human umbilical cords blood or adipose tissues were used in $24.2 \%$ of the studies. Besides, one study included MSCs derived from primary human pancreatic cancer tissues. The ratio of tumor cells to MSCs varied between 0.01 and 50, while the number of administrated MSCs was consistent with the number of injected tumor cells in most experiments (48.5\%). MSCs were generally administrated as a single does together with tumor cells, and in $22.7 \%$ experiments animals received multiple MSCs injections via tail vein within 5 weeks following tumor cells injections.

Out of the 39 studies, only 14 of them reported the passages of MSCs they used, and 16 of them identified MSCs by verified the potentials of multilineage differentiation, with most studies failed to report the passages and differentiation potentials of the MSCs used.

\section{Study quality and risk of bias}

The quality assessment of the 39 studies was shown in Fig. 2. In most cases, poor reporting resulted in an unclear risk of bias. Take selection bias as an example, almost no author described the randomization 
Table 1 Characteristics of reviewed 39 publications with 66 comparisons (number $=66$ )

\begin{tabular}{|c|c|c|}
\hline Characteristics & Subgroups & Number (\%) \\
\hline \multirow[t]{6}{*}{ Cancer type } & Breast cancer $[2,9,12,17,18,21,32-40]$ & $32(48.5)$ \\
\hline & Osteosarcoma [11, 19, 41-43] & $8(12.1)$ \\
\hline & Hepatocellular carcinoma $[5,13,44]$ & $6(9.1)$ \\
\hline & Colon cancer [45-47] & $4(6.1)$ \\
\hline & Melanoma $[20,48,49]$ & $3(4.5)$ \\
\hline & Other $[10,50-58]$ & $13(19.7)$ \\
\hline \multirow[t]{3}{*}{ Animal species/strain } & Nude mice $[2,5,9-13,18,19,21,32-40,43-47,50-54,56-58]$ & $55(83.3)$ \\
\hline & Other mice $[17,20,48,49,55]$ & $6(9.1)$ \\
\hline & Rat $[41,42]$ & $5(7.6)$ \\
\hline \multirow[t]{3}{*}{ Animal gender } & Female $[2,12,17,18,20,33-37,39,40,43,46,47,50,51,53,55,56]$ & $35(53.0)$ \\
\hline & Male $[5,10,11,19,42,45,49,54]$ & $12(18.2)$ \\
\hline & Unclear $[9,13,21,32,38,41,44,48,52,57,58]$ & $19(28.8)$ \\
\hline \multirow[t]{5}{*}{ Source of MSCs } & Human bone marrow $[2,9-13,18,21,32,34,35,43-47,52,54,56]$ & $30(45.5)$ \\
\hline & Other human tissue $[5,33,36-38,50,53,57]$ & $16(24.2)$ \\
\hline & Mice bone marrow $[20,35,39,40,48,49,55,58]$ & $11(16.7)$ \\
\hline & Rat mone marrow $[41,42,51]$ & $6(9.1)$ \\
\hline & Unclear $[17,19]$ & $3(4.5)$ \\
\hline \multirow[t]{3}{*}{ Cancer cell/MSCs dose ratio } & $<1[2,20,33,39,46,47,49,54,55]$ & $15(22.7)$ \\
\hline & $=1[5,9,12,13,17,19,21,32,36,40-42,44,45,48,50,51,53,57,58]$ & $32(48.5)$ \\
\hline & $>1[10,11,18,34,35,37,38,43,52,56]$ & $19(28.8)$ \\
\hline \multirow[t]{2}{*}{ Timing of MSCs administration } & Co-administration $[2,5,9,10,17-19,21,32-34,36,38-43,45-48,50,52-55,58]$ & $47(71.2)$ \\
\hline & Followed administration $[11-13,20,35-37,41,44,49,51,56]$ & $19(28.8)$ \\
\hline \multirow[t]{2}{*}{ MSCs passages } & Reported $(3-20)[2,12,13,19,20,32,35,37,42,44,49-52]$ & $25(37.9)$ \\
\hline & Unclear $[5,9-11,17,18,21,33,34,36,38-41,43,45-48,53-58]$ & $41(62.1)$ \\
\hline \multirow[t]{2}{*}{ MSCs differentiation } & With $[18,20,21,32,33,35,39,43,45,46,48,50,52,53,56,57]$ & $25(37.9)$ \\
\hline & Without $[2,5,9-13,17,19,34,36-38,40-42,44,47,49,51,54,55,58]$ & $41(62.1)$ \\
\hline \multirow[t]{3}{*}{ Metastasis site } & Lung $[2,5,9,11-13,17-21,32,33,35-40,42-45,49,51,54,56,58]$ & $41(62.1)$ \\
\hline & Liver $[18,33,35,46,47,52,57]$ & $7(10.6)$ \\
\hline & Other organ or multiple organ $[9,10,17,18,32,34,48,53,55]$ & $18(27.3)$ \\
\hline
\end{tabular}

procedures or whether the sequence had been concealed. However, the majority of studies seemed to be similar at animal baseline. Performance bias was reflected by item 4 and 5. As shown in Fig. 2, none of the authors reported the measures to reduce the performance bias. Measures to reduce detection bias (item 6 and 7) were mentioned in a small part of studies, though the specific methods to achieve randomization for outcome assessment were not reported. Concerning the risk of attrition bias (item 8), most studies were low risk of bias, while $18.4 \%$ high risk and $21.1 \%$ unclear. Date to assess the risk of reporting bias (item 9) were incomplete in studies included, leading to an unclear risk of bias.

Considering the fact that only limited details on most animals' studies were provided, we scored another three items as described in the method section. As shown in Fig. 2, most studies were low risk of inappropriate fund bias (81.6\%). Randomization of the studies at any level was reported in $31.6 \%$ publications. And blinding at any level was reported in $5.3 \%$ publications.

According to whether the publication meets the 12 items listed above, we classify the publications into three categories. Among all the 39 publications, no study has reached 9-12 criteria, only seven publications have met 5-8 criteria, and 32 publications have met $0-4$ criteria.

\section{Meta-analysis of the effect size: incidence of tumor metastases}

A total of 31 comparisons with 624 animals investigating the effect of MSCs administration on the incidence of tumor metastases in experimental animal models were involved in the meta-analysis. Overall, the results found the administration of MSCs increased the incidence of tumor metastases in animal models (RR 2.04, and 95\% CI 1.57-2.65, Fig. 3), with a mild heterogeneity between studies $\left(\mathrm{I}^{2}=21 \%\right)$. 
1) Was the allocation sequence adequately generated and applied? 2)Were the groups similar at baseline or were 3)Was the allocation to the different groups adequately concealed during? 4)Were the animals randomly housed during the experiment? 5)Were the caregivers and/or investigators blinded from knowledge which intervention ezch animal received during experiment? 6)Were animals selected at random for outcome assessment?

7)Was the outcome assessor blinded?

8)Were incomplete outcome data adequately addressed? 9)Are reports of the study free of selective outcome reporting? 10)Was the study free of inappropriate influence of funders? 11)Was the study stated the experiment was randomized at any level? 12)Was the study stated the experiment was blinded at any level?

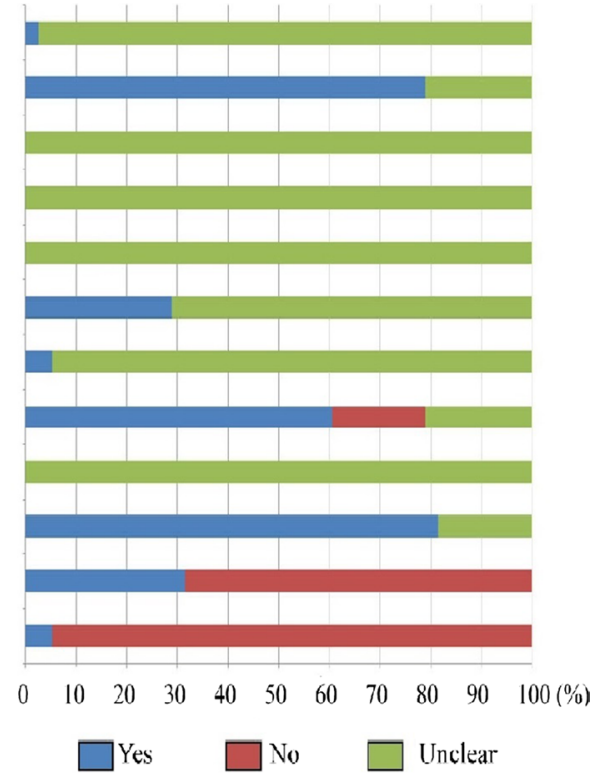

Fig. 2 Proportion of studies meeting each quality score criterion. Results of the risk of bias of the 39 studies involved in the systematic review were shown by bar charts. For the items 1 to 10, "Yes" means that the description of measurements meets the item requirements, indicating low risk of bias, "No" means that the description does not meet the item requirements, indicating high risk of bias, and "Unclear" means there is no relevant reports, indicating unclear risk of bias. With the item 11 and 12, "Yes" indicated reported and "No" indicated unreported

Subgroup analyses were performed based on experiment design, to examine whether particular factors may affect the outcome of meta-analysis. The effects of MSCs on the incidence of cancer metastasis were robust across cancer type, cancer metastasis site, animal models, as well as MSCs delivery timing, source, and dose (Table 2). Also, no significant impact of quality assessment category on effect size was observed $(p=0.63)$. Besides, considering that the quality and risk of bias due to poor reporting in most cases was not clear, experiments were also grouped according to the impact factors (IFs) of the journal. And it found the effects were robust across these two groups $(p=0.58)$.

Heterogeneity within the subgroup was remarkably reduced when cancer type, metastasis estimation methods, MSCs administration way, and IFs were limited. For example, subgroup analysis for breast cancer, which weighted $45.8 \%$, found an effect size RR 1.94 (95\% CI $\left.1.43-2.62, \mathrm{I}^{2}=0 \%\right)$. Subgroup analysis for bioluminescence measurement of metastasis, which weighted $48.2 \%$, found an effect size RR 2.13 (95\% CI 1.59-2.84, $\mathrm{I}^{2}=0 \%$ ). Subgroup of co-administration of cancer cells and MSC, weighted 73.6\%, found an effect size RR 2.19 (95\% CI $1.72-2.79, \mathrm{I}^{2}=0 \%$ ), and subgroup of higher IFs, weighted 50.7\%, found an effect size RR 2.21 (95\% CI 1.66-2.95, $\mathrm{I}^{2}=0 \%$ ). What's more, it shown cancer cells/MSCs injection ratio may be the main source of heterogeneity $\left(p=0.03\right.$, heterogeneity between subgroups $\left.\mathrm{I}^{2}=71.6 \%\right)$.
However, because the number of studies in the subgroup of cancer cells/MSCs ratio $<1$ was small, the results should be interpreted with cautions.

\section{Meta-analysis of the effect size: number of tumor metastases}

A total of 35 comparisons with 489 animals were involved in the meta-analysis, which investigating the effect of MSCs administration on the number of tumor metastases. The results found the administration of MSCs increased the number of tumor metastases in experimental cancer models (SMD 1.23, and 95\% CI 0.43-2.03, Fig. 4). The heterogeneity between studies was significant $\left(\mathrm{I}^{2}=89 \%\right)$, demonstrating notable heterogeneity across studies.

Subgroup analyses were shown in Table 3. It revealed the effects varied across the way MSCs administrated (both dose and timing), the study length, and impact factors of published journal. But no significant impact of quality assessment category on effect size was observed $(p=0.07)$. Subgroups of co-administration of cancer cells and MSCs, study length longer than 42 days, and journals had higher impact factors (IF $>5)$ had reduced heterogeneity.

To rule out the influence of cancer type on heterogeneity, experiments of breast cancer were selected and further subgroup analyses were performed. It also revealed study length and different ways of metastasis 


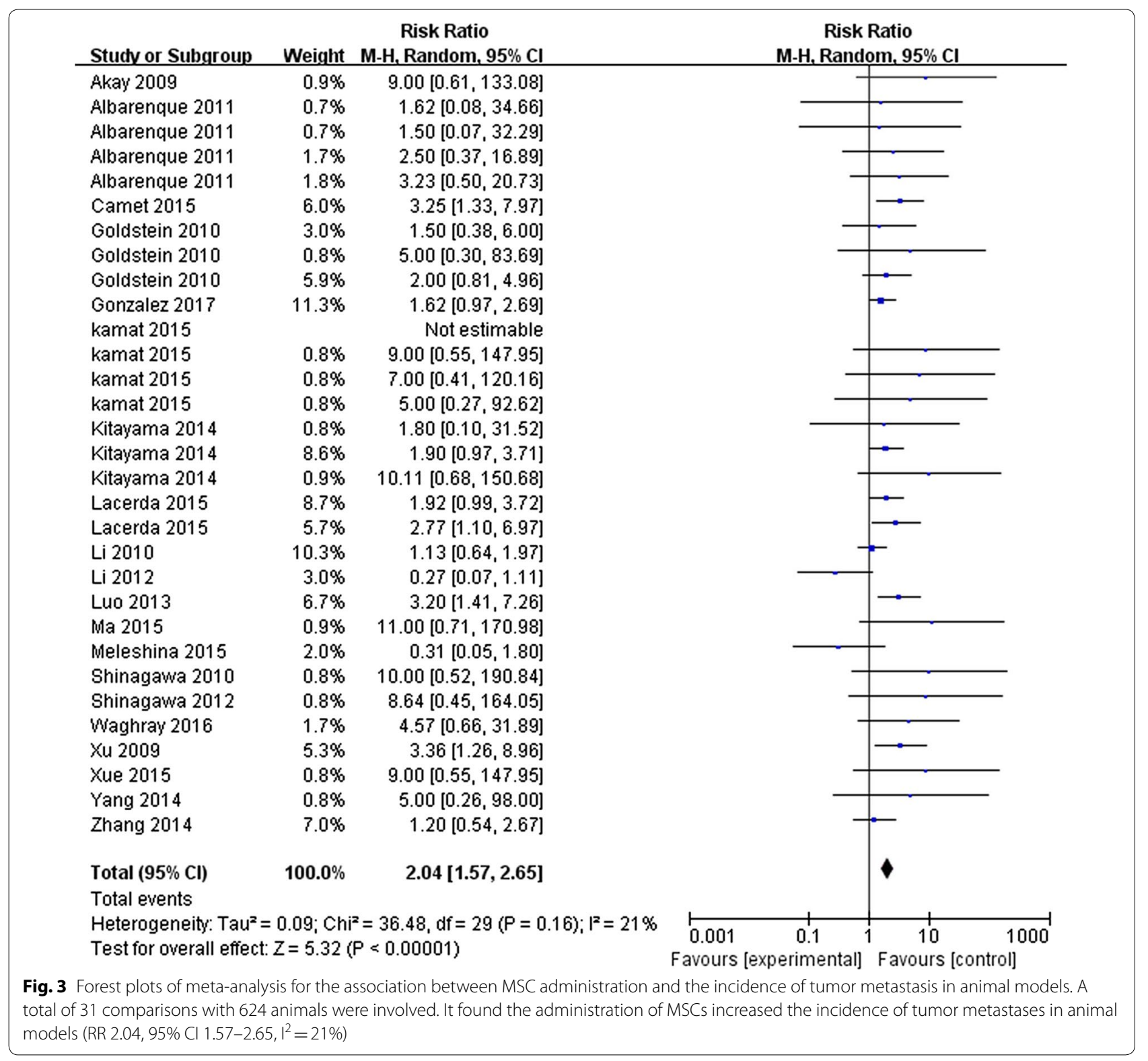

measurement or MSCs administration could be the main sources of heterogeneity (Table 4). For example, subgroup analysis for histological measurement of metastasis found an effect size SMD 2.92 (95\% CI 1.82-4.02, $\left.\mathrm{I}^{2}=55 \%\right)$. Whereas subgroup for fluorescence measurement found an effect size SMD 1.22 (95\% CI - 0.2 2.65, $\left.\mathrm{I}^{2}=90 \%\right)$.

\section{Sensitivity analysis}

To assess the robustness of the estimated pooled effect size for metastases number and incidence, we performed a leave-one-out sensitivity analysis by removing one study at a time and reevaluating the effect size of the remaining studies. For both the number and the incidence of metastases, the pooled effect was stable, indicating the results were not driven by any single study.

\section{Publication bias}

Publication bias was assessed by funnel plot for the outcomes of metastases number and incidence. Figure $5 \mathrm{a}$ suggested a symmetrical distribution for the number of metastases. But funnel plot demonstrated some degree of asymmetry for the incidence of metastases, indicating the possibility of either publication bias or a systematic difference between the studies (Fig. 5b). 
Table 2 Effect size and subgroup analyses for MSC administration in preclinical studies of solid tumor metastasis incidence

\begin{tabular}{|c|c|c|c|c|c|c|}
\hline \multirow[t]{2}{*}{ Group } & \multirow{2}{*}{$\begin{array}{l}\text { Weight } \\
\text { (\%) }\end{array}$} & \multicolumn{2}{|c|}{ Effect size } & \multirow{2}{*}{$\begin{array}{l}1^{2 a} \\
(\%)\end{array}$} & \multirow[t]{2}{*}{$P$} & \multirow{2}{*}{$\begin{array}{l}\mathrm{I}^{\mathbf{2 b}} \\
(\%)\end{array}$} \\
\hline & & RR & $95 \% \mathrm{Cl}$ & & & \\
\hline All experiments & 100.0 & 2.04 & $1.57,2.65$ & 21 & & \\
\hline \multicolumn{7}{|l|}{ Cancer type } \\
\hline Breast cancer & 45.8 & 1.94 & $1.43,2.62$ & 0 & 0.630 & 0 \\
\hline Other cancer & 54.2 & 2.22 & $1.41,3.50$ & 21 & & \\
\hline \multicolumn{7}{|l|}{ Animal species/strain } \\
\hline Nude mice & 86.2 & 2.03 & $1.53,2.68$ & 19 & 0.810 & 0 \\
\hline Other mice/rat & 13.8 & 2.30 & $0.85,6.22$ & 54 & & \\
\hline \multicolumn{7}{|l|}{ Source of MSC } \\
\hline Human bone marrow & 65.1 & 1.81 & $1.24,2.64$ & 42 & 0.450 & 0 \\
\hline Other human tissue & 16.1 & 2.77 & $1.61,4.77$ & 0 & & \\
\hline Mice/rat bone marrow & 18.8 & 2.09 & $1.24,3.51$ & 0 & & \\
\hline \multicolumn{7}{|l|}{ Metastasis estimation } \\
\hline Fluorescence microscopy & 17.2 & 2.95 & $1.32,6.60$ & 27 & 0.610 & 0 \\
\hline Histological evaluation & 34.6 & 1.79 & $1.03,3.14$ & 38 & & \\
\hline Bioluminescence & 48.2 & 2.13 & $1.59,2.84$ & 0 & & \\
\hline \multicolumn{7}{|l|}{ Cancer cell/MSC dose ratio } \\
\hline$=1$ & 47.2 & 1.39 & $0.9,2.16$ & 38 & 0.030 & 71.6 \\
\hline$>1$ & 45.3 & 2.62 & $1.89,3.65$ & 0 & & \\
\hline$<1$ & 7.5 & 3.83 & $1.68,8.73$ & 0 & & \\
\hline \multicolumn{7}{|l|}{ Timing of MSC administration } \\
\hline Co-administration & 73.6 & 2.19 & $1.72,2.79$ & 0 & 0.240 & 28.5 \\
\hline Follow-administration & 26.4 & 1.39 & $0.68,2.84$ & 48 & & \\
\hline \multicolumn{7}{|l|}{ Study length (days) } \\
\hline$\leq 42$ & 100 & 2.04 & $1.57,2.65$ & 21 & - & - \\
\hline$>42$ & 0 & - & - & - & & \\
\hline \multicolumn{7}{|l|}{ Metastasis site } \\
\hline Lung & 55.4 & 1.61 & $1.08,2.40$ & 34 & 0.060 & 72 \\
\hline Other tissue & 44.6 & 2.64 & $1.92,3.63$ & 0 & & \\
\hline \multicolumn{7}{|l|}{ Study quality category } \\
\hline Meet 9-12 criteria & 0 & - & - & - & 0.630 & 0 \\
\hline Meet 5-8 criteria & 9.2 & 2.90 & $0.74,11.40$ & 37 & & \\
\hline Meet 0-4 criteria & 90.8 & 2.06 & $1.56,2.71$ & 21 & & \\
\hline \multicolumn{7}{|l|}{ Impact factor of journal } \\
\hline$\leq 5$ & 49.3 & 1.90 & $1.19,3.01$ & $36 \%$ & 0.580 & 0 \\
\hline$>5$ & 50.7 & 2.21 & $1.66,2.95$ & 0 & & \\
\hline
\end{tabular}

$R R$ risk ratio; $C l$ confidence interval; $P^{2 a}, I^{2}$ for heterogeneity within each subgroup; $P P$ value for heterogeneity between subgroups; $I^{2 b}, l^{2}$ for heterogeneity between subgroups

\section{Discussion}

It has been reported that there might be a relation between MSCs and the outgrowth of cancer metastasis [5, 16-18]. Solid preclinical analysis, however, has been lacking so far. The current meta-analysis examined the effect of MSCs on cancer metastasis in current stateof-the-art preclinical studies. We provide evidence that MSCs usage increase the number and the incidence of cancer metastasis in experimental cancer models.
To our knowledge, no studies have examined the effects of MSCs on solid tumor metastasis in animal models using a meta-analysis. Our meta-analysis suggested MSCs increased the number and the incidence of tumor metastases in animal models (SMD 1.23, 95\% CI 0.43-2.03; RR 2.04, 95\% CI 1.57-2.65, respectively). These studies advanced our understanding of the prometastasis properties of MSCs during tumor metastasis. More specifically, as shown in Additional file 2: Figure 


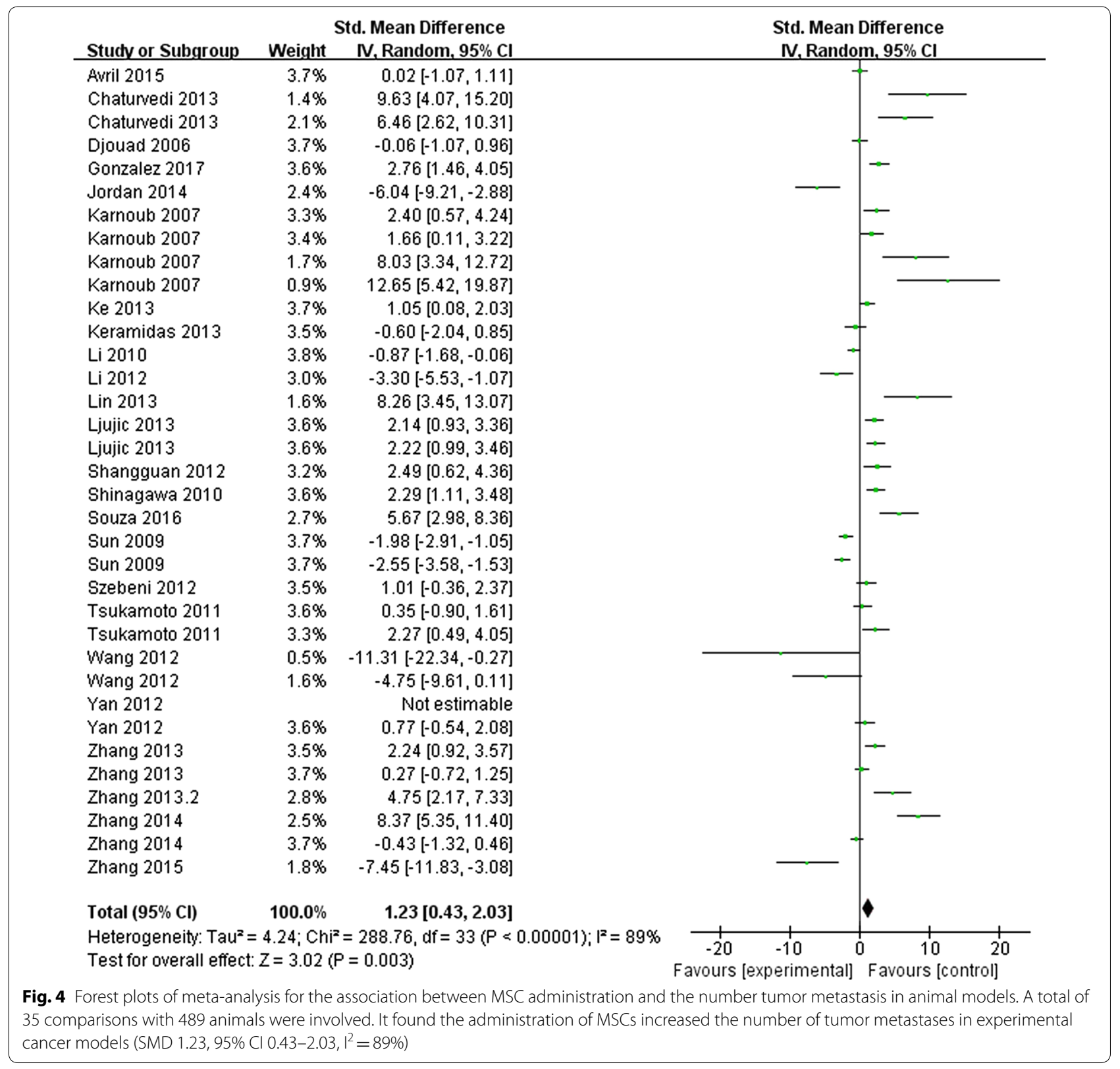

S1, MSCs could produce large amounts of factors and exosomes to promote cancer cell invasion, angiogenic process, or prepare tissue niches in distant organs $[6,19]$. MSCs could also affect cancer cells by cell-cell contact. Moreover, MSCs could recruit several immunosuppressive stroma cells such as myeloid-derived suppressor cells (MDSCs) by creating chemokines [20]. Notably, these pro-metastasis properties of MSCs might transiently expressed in response to context signals, such as hypoxia in tumor niches, rather than constitutively expressed $[9,21,22]$. However, as cell lines study has its intrinsic limitation, the conclusions and underlying mechanisms should be explained with cautions. And it is important to implement studies on primary biopsy material to demonstrate the effect of MSCs.

In general, an effect size of 0.8 equates to a large effect, 0.5 to a medium effect, and 0.2 to a small effect [23]. In this context, the effects of MSCs on cancer metastasis can be classified as large, for example, for number of metastasis averaging 1.23 and incidence of metastasis averaging 2.04 across all comparisons. In this study, effects of MSCs on the incidence of cancer metastasis were robust across cancer type, cancer metastasis site, animal models, as well as MSCs delivery timing, source, and dose (Table 2). 
Table 3 Effect size and subgroup analyses for MSC administration in preclinical studies of solid tumor metastasis number

\begin{tabular}{|c|c|c|c|c|c|c|}
\hline \multirow[t]{2}{*}{ Group } & \multirow{2}{*}{$\begin{array}{l}\text { Weight } \\
(\%)\end{array}$} & \multicolumn{2}{|c|}{ Effect size } & \multirow{2}{*}{$\begin{array}{l}1^{2 a} \\
(\%)\end{array}$} & \multirow[t]{2}{*}{$P$} & \multirow{2}{*}{$\begin{array}{l}1^{2 \mathbf{b}} \\
(\%)\end{array}$} \\
\hline & & SMD & $95 \% \mathrm{Cl}$ & & & \\
\hline All experiments & 100.0 & 1.23 & $0.43,2.03$ & 89 & & \\
\hline \multicolumn{7}{|l|}{ Cancer type } \\
\hline Breast cancer & 48.6 & 2.04 & $0.87,3.21$ & 90 & 0.060 & 71.8 \\
\hline Other cancer & 51.4 & 0.48 & $-0.65,1.61$ & 89 & & \\
\hline \multicolumn{7}{|l|}{ Animal species/strain } \\
\hline Nude mice & 82.3 & 1.12 & $0.26,1.97$ & 89 & 0.690 & 0 \\
\hline Other mice/rat & 17.7 & 1.67 & $-0.9,4.23$ & 92 & & \\
\hline \multicolumn{7}{|l|}{ Source of MSC } \\
\hline Human bone marrow & 40.7 & 1.96 & $0.59,3.33$ & 87 & 0.330 & 12.4 \\
\hline Other human tissue & 18.2 & 0.09 & $-1.94,2.13$ & 94 & & \\
\hline Mice/rat bone marrow & 31.0 & 0.73 & $-0.72,2.17$ & 89 & & \\
\hline Unclear & 10.0 & 2.15 & $-0.14,4.34$ & 85 & & \\
\hline \multicolumn{7}{|l|}{ Metastasis estimation } \\
\hline Fluorescence microscopy & 42.0 & 1.11 & $-0.3,2.35$ & 90 & 0.170 & 44.2 \\
\hline Histological evaluation & 40.1 & 2.02 & $0.76,3.29$ & 88 & & \\
\hline Bioluminescence & 17.9 & -0.54 & $-2.95,1.87$ & 89 & & \\
\hline \multicolumn{7}{|l|}{ Cancer cell/MSC dose ratio } \\
\hline$=1$ & 62.6 & 1.11 & $0.1,2.12$ & 90 & 0.030 & 72.7 \\
\hline$>1$ & 7.2 & -0.20 & $-1.08,0.67$ & 0 & & \\
\hline$<1$ & 30.2 & 1.85 & $0.45,3.24$ & 80 & & \\
\hline \multicolumn{7}{|l|}{ Timing of MSC administration } \\
\hline Co-administration & 68.5 & 2.18 & $1.38,2.99$ & 82 & 0.001 & 94 \\
\hline Follow-administration & 31.5 & -1.13 & $-2.50,0.23$ & 88 & & \\
\hline \multicolumn{7}{|l|}{ Study length (days) } \\
\hline$\leq 42$ & 59.1 & 0.32 & $-0.70,1.35$ & 91 & 0.006 & 86.7 \\
\hline$>42$ & 40.9 & 2.44 & $1.32,3.56$ & 78 & & \\
\hline \multicolumn{7}{|l|}{ Metastasis site } \\
\hline Lung & 81.6 & 1.80 & $0.28,2.07$ & 89 & 0.570 & 0 \\
\hline Other tissue & 18.4 & 1.66 & $0.26,3.07$ & 73 & & \\
\hline \multicolumn{7}{|l|}{ Study quality category } \\
\hline Meet 9-12 criteria & 0 & - & - & - & 0.07 & 70.5 \\
\hline Meet 5-8 criteria & 20.3 & 2.92 & $0.90,4.94$ & 90 & & \\
\hline Meet 0-4 criteria & 79.7 & 0.85 & $-0.04,1.74$ & 89 & & \\
\hline \multicolumn{7}{|l|}{ Impact factor of journal } \\
\hline$\leq 5$ & 56.8 & 0.30 & $-0.73,1.32$ & 89 & 0.004 & 87.7 \\
\hline$>5$ & 43.2 & 2.30 & $1.38,3.22$ & 74 & & \\
\hline
\end{tabular}

$S M D$ standard mean difference; $C l$ confidence interval; $P^{2 a}, I^{2}$ for heterogeneity within each subgroup; $P P$ value for heterogeneity between subgroups; $P^{2 b}, I^{2}$ for heterogeneity between subgroups

The quality of the studies was also reviewed, using SYRCLE's risk of bias tool for animal studies [15]. We found that the risk of bias could not be estimated in most studies for each item assessed, indicating a poor reported risk of bias. Only seven publications have met more than four items out of the 12 criteria. Though no significant impact of quality assessment category on effect size was observed $(p=0.07$ for the number of cancer metastasis and $p=0.63$ for the incidence of cancer metastasis), and current reporting quality of pre-clinical studies is generally poor, it may be associated with inflations in the estimates of the effect size [24-27]. Moreover, methodological weakness in animal studies could result in over-estimated treatment effects and decrease confidence in translational potential [25]. Thus, further pre-clinical studies with high reporting quality of essential experimental details is needed. 
Table 4 Effect size and subgroup analyses for MSC administration in preclinical studies of breast cancer metastasis number

\begin{tabular}{|c|c|c|c|c|c|c|}
\hline \multirow[t]{2}{*}{ Group } & \multirow{2}{*}{$\begin{array}{l}\text { Weight } \\
\text { (\%) }\end{array}$} & \multicolumn{2}{|c|}{ Effect size } & \multirow{2}{*}{$\begin{array}{l}\mathrm{I}^{2 a} \\
(\%)\end{array}$} & \multirow[t]{2}{*}{$P$} & \multirow{2}{*}{$\begin{array}{l}1^{2 \mathbf{b}} \\
(\%)\end{array}$} \\
\hline & & SMD & $95 \% \mathrm{Cl}$ & & & \\
\hline All experiments & 100.0 & 2.04 & $0.87,3.21$ & 90 & & \\
\hline \multicolumn{7}{|l|}{ Animal species/strain } \\
\hline Nude mice & 100 & 2.04 & $0.87,3.21$ & 90 & - & - \\
\hline Other mice/rat & 0 & - & - & - & & \\
\hline \multicolumn{7}{|l|}{ Source of MSC } \\
\hline Human bone marrow & 40.3 & 4.06 & $2.43,5.70$ & 70 & 0.006 & 75.8 \\
\hline Other human tissue & 30 & -0.07 & $-2.54,2.41$ & 95 & & \\
\hline Mice/rat bone marrow & 14.8 & 1.04 & $0.24,1.83$ & 0 & & \\
\hline Unclear & 14.9 & 1.20 & $-0.73,3.14$ & 82 & & \\
\hline \multicolumn{7}{|l|}{ Metastasis estimation } \\
\hline Fluorescence microscopy & 64.1 & 1.22 & $-0.2,2.65$ & 90 & 0.07 & 70.5 \\
\hline Histological evaluation & 35.9 & 2.92 & $1.82,4.02$ & 55 & & \\
\hline Bioluminescence & 0 & - & - & - & & \\
\hline \multicolumn{7}{|l|}{ Cancer cell/MSC dose ratio } \\
\hline$=1$ & 58.8 & 1.48 & $-0.14,3.1$ & 92 & 0.35 & 0 \\
\hline$>1$ & 0 & - & - & - & & \\
\hline$<1$ & 41.2 & 2.44 & $1.27,3.62$ & 65 & & \\
\hline \multicolumn{7}{|l|}{ Timing of MSC administration } \\
\hline Co-administration & 84.8 & 2.38 & $1.54,3.22$ & 72 & 0.001 & 98 \\
\hline Follow-administration & 15.2 & -2.24 & $-2.93,1.55$ & 0 & & \\
\hline \multicolumn{7}{|l|}{ Study length (days) } \\
\hline$\leq 42$ & 44.8 & 0.29 & $-1.42,2.00$ & 93 & 0.008 & 85.7 \\
\hline$>42$ & 55.2 & 3.24 & $1.88,4.6$ & 78 & & \\
\hline \multicolumn{7}{|l|}{ Metastasis site } \\
\hline Lung & 75.6 & 1.80 & $0.47,3.12$ & 90 & 0.680 & 0 \\
\hline Other tissue & 24.4 & 2.20 & $0.84,3.56$ & 60 & & \\
\hline \multicolumn{7}{|l|}{ Impact factor of journal } \\
\hline$\leq 5$ & 30 & -0.64 & $-2.52,1.23$ & 92 & 0.002 & 90 \\
\hline$>5$ & 70 & 2.8 & $1.78,3.82$ & 73 & & \\
\hline
\end{tabular}

$S M D$ standard mean difference; $C l$ confidence interval; $P^{2 a}, I^{2}$ for heterogeneity within each subgroup; $P P$ value for heterogeneity between subgroups; $l^{2 b}, I^{2}$ for heterogeneity between subgroups

Besides, heterogeneity was observed in current metaanalyses. On one hand, based on this review, the level of heterogeneity between the studies for the incidence of cancer metastasis was low $\left(\mathrm{I}^{2}=21 \%\right)$, suggesting that incidence of metastasis might be an efficient indicator of effect of MSCs on cancer metastasis. On the other hand, the level of heterogeneity between the studies for the number of cancer metastasis was relatively high $\left(\mathrm{I}^{2}=89 \%\right)$, though the $\mathrm{I}^{2}$ values were similar to the values reported by other studies focused on animal studies $[24,28,29]$. Further subgroup analysis, to some extent, revealed some possibilities of heterogeneity, such as study length, methods of metastasis measurement and MSCs administration. We observed that short-term study length ( $\leq 42$ days), metastasis count by fluorescence intensity rather than histological measurement, and MSCs intravenously injected more than once after primary tumor implanted may induce high heterogeneity. To some extent, this might help to inform the design of future animal studies.

Since MSCs are a heterogeneous population of cells, it is relevant to view the source of MSCs and the techniques used to isolate and characterize MSCs in original studies $[6,7,30,31]$. Among all the 39 studies involved in present meta-analysis, however, only 16 studies reported on multi-lineage differentiation for MSCs and 14 studies reported on cell passages of MSCs used. Also, these studies used different sets 


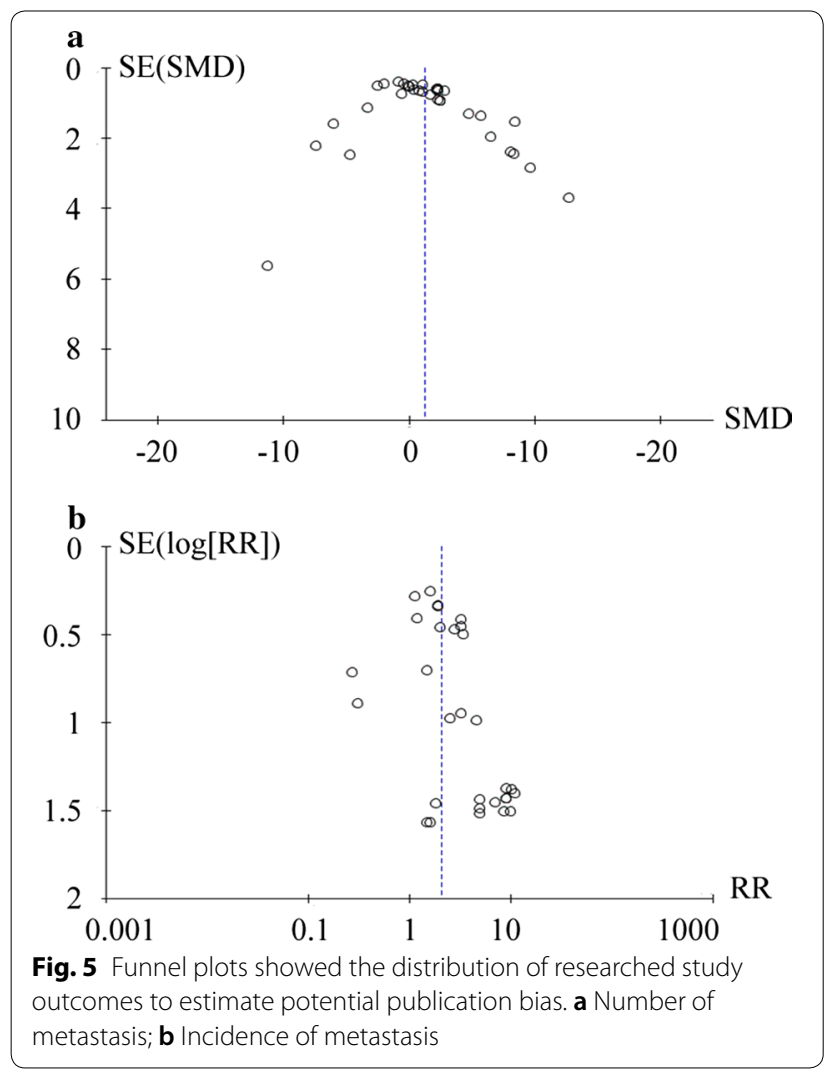

of molecular or phenotypic pattern to characterize MSCs. These differences in cell isolation and identification might favor certain subpopulations, which could result in the heterogeneity. Thus, further studies should pay more attention to the methods which clarified the population of stromal cells that used experimentally, to enable adequate analysis across different studies.

Finally, this review has several limitations. First, we could not rule out that the effect of MSCs could be less strong or not effective in certain subgroups of unpublished data, since the visualization of the funnel plot suggested some extent of publication bias. Second, the level of heterogeneity between the studies for the number of cancer metastasis was high, though random effects models were used to account for anticipated heterogeneity. Thus the substantial heterogeneity found through this review may restrict the generalizability of the findings. Third, there were only 39 publications met the inclusion criteria, though 744 literatures were identified by electronic searching. Nevertheless, at the very least our analysis represents the complete review for unmodified-MSCs administration in experimental cancer metastasis.

\section{Conclusion}

The present meta-analysis demonstrated the favorable impact of MSCs on cancer metastasis, both the incidence and the number, in experimental cancer models. Although poor reported risk of bias and high level of heterogeneity were yet limited, at the very least, the current meta-analysis underlined that MSCs might have an active role in tumor microenvironment and might represent a promising target to therapies preventing the establishment of cancer distant metastasis. Still further preclinical studies with better design and adequate reporting are needed.

\section{Additional files}

Additional file 1: Table S1. The detail characteristics of all the publications included.

Additional file 2: Figure S1. MSCs with promoting effects on tumor metastasis.

\section{Abbreviations}

MSCs: mesenchymal stem cells; SMD: standardized mean difference; RR: risk ration; 95\% Cl: 95\% confidence intervals; MDSCs: myeloid-derived suppressor cells.

\section{Authors' contributions}

RZG designed and supervised the study. LH, FWS, and WMM collected all data, performed the statistical analysis and drafted the report. RZG and WYH participated in the interpretation of the data and critically reviewed the report. All authors read and approved the final manuscript.

\section{Author details}

${ }^{1}$ Key Laboratory of Carcinogenesis and Cancer Invasion, Ministry of Education, Shanghai 200032, China. ${ }^{2}$ Liver Cancer Institute, Zhongshan Hospital, Fudan University, Shanghai 200032, China. ${ }^{3}$ Ruijin Hospital, Shanghai Jiaotong University School of Medicine, Shanghai 200025, China. ${ }^{4}$ Department of Orthopedics, Zhongshan Hospital, Fudan University, Shanghai 200032, China.

\section{Acknowledgements}

None.

\section{Competing interests}

The authors declare that they have no competing interests.

\section{Availability of data and materials}

All data generated or analyzed during this study are included in this published article and additional information files.

Consent for publication

Not applicable.

Ethics approval and consent to participate

Not applicable.

\section{Funding}

This work was supported by the National Clinical Key Special Subject of China and Nation Natural Science Foundation of China (No. 81172275 and No. 81272565).

\section{Publisher's Note}

Springer Nature remains neutral with regard to jurisdictional claims in published maps and institutional affiliations. 
Received: 3 January 2018 Accepted: 17 April 2018

Published online: 27 April 2018

\section{References}

1. Jin K, Li T, van Dam H, Zhou F, Zhang L. Molecular insights into tumour metastasis: tracing the dominant events. J Pathol. 2017;241:567-77.

2. Karnoub AE, Dash AB, Vo AP, Sullivan A, Brooks MW, Bell GW, et al. Mesenchymal stem cells within tumour stroma promote breast cancer metastasis. Nature. 2007:449:557-63.

3. Cotanche DA, Sepulveda R, Rogers RA. Effect of pericytes on melanoma development. J Clin Oncol. 2012;30:83.

4. Dou YN, Chaudary N, Chang MC, Dunne M, Huang H, Jaffray DA, et al. Tumor microenvironment determines response to a heat-activated thermosensitive liposome formulation of cisplatin in cervical carcinoma. J Control Release. 2017;262:182-91.

5. Yan XL, Jia YL, Chen L, Zeng Q, Zhou JN, Fu CJ, et al. Hepatocellular carcinoma-associated mesenchymal stem cells promote hepatocarcinoma progression: role of the S100A4-miR155-SOCS1-MMP9 axis. Hepatology. 2013;57:2274-86

6. Shi Y, Du L, Lin L, Wang Y. Tumour-associated mesenchymal stem/stromal cells: emerging therapeutic targets. Nat Rev Drug Discov. 2017;16:35-52.

7. Fan W, Li J, Wang Y, Pan J, Li S, Zhu L, et al. CD105 promotes chondrogenesis of synovium-derived mesenchymal stem cells through Smad2 signaling. Biochem Biophys Res Commun. 2016;474:338-44.

8. Ridge SM, Sullivan FJ, Glynn SA. Mesenchymal stem cells: key players in cancer progression. Mol Cancer. 2017;16:31.

9. Chaturvedi P, Gilkes DM, Wong CC, Luo W, Zhang H, Wei H, et al. Hypoxiainducible factor-dependent breast cancer-mesenchymal stem cell bidirectional signaling promotes metastasis. J Clin Invest. 2013;123:189-205.

10. Luo J, Ok LS, Liang L, Huang CK, Li L, Wen S, et al. Infiltrating bone marrow mesenchymal stem cells increase prostate cancer stem cell population and metastatic ability via secreting cytokines to suppress androgen receptor signaling. Oncogene. 2014;33:2768-78.

11. Xu WT, Bian ZY, Fan QM, Li G, Tang TT. Human mesenchymal stem cells (hMSCs) target osteosarcoma and promote its growth and pulmonary metastasis. Cancer Lett. 2009;281:32-41.

12. Meleshina AV, Cherkasova El, Shirmanova MV, Klementieva NV, Kiseleva EV, Snopova LB, et al. Influence of mesenchymal stem cells on metastasis development in mice in vivo. Stem Cell Res Ther. 2015;6:15

13. Li GC, Ye QH, Dong QZ, Ren N, Jia HL, Qin LX. Mesenchymal stem cells seldomly fuse with hepatocellular carcinoma cells and are mainly distributed in the tumor stroma in mouse models. Oncol Rep. 2013;29:713-9.

14. Moher D, Liberati A, Tetzlaff J, Altman DG. Preferred reporting items for systematic reviews and meta-analyses: the PRISMA statement. Int I Surg. 2010;8:336-41.

15. Hooijmans $C R$, Rovers MM, de Vries RB, Leenaars M, Ritskes-Hoitinga M, Langendam MW. SYRCLE's risk of bias tool for animal studies. BMC Med Res Methodol. 2014;14:43.

16. Zhang Y, Yang P, Sun T, Li D, Xu X, Rui Y, et al. miR-126 and miR-126* repress recruitment of mesenchymal stem cells and inflammatory monocytes to inhibit breast cancer metastasis. Nat Cell Biol. 2013;15:284-94.

17. Zhang XH, Jin X, Malladi S, Zou Y, Wen YH, Brogi E, et al. Selection of bone metastasis seeds by mesenchymal signals in the primary tumor stroma. Cell. 2013;154:1060-73.

18. Goldstein RH, Reagan MR, Anderson K, Kaplan DL, Rosenblatt M. Human bone marrow-derived MSCs can home to orthotopic breast cancer tumors and promote bone metastasis. Cancer Res. 2010;70:10044-50.

19. Zhang $P$, Dong L, Yan $K$, Long H, Yang TT, Dong MQ, et al. CXCR4-mediated osteosarcoma growth and pulmonary metastasis is promoted by mesenchymal stem cells through VEGF. Oncol Rep. 2013;30:1753-61.

20. Souza LE, Almeida DC, Yaochite JN, Covas DT, Fontes AM. Intravenous administration of bone marrow-derived multipotent mesenchymal stromal cells enhances the recruitment of CD11b(+) myeloid cells to the lungs and facilitates B16-F10 melanoma colonization. Exp Cell Res. 2016;345:141-9.

21. Shangguan $L$, Ti X, Krause U, Hai B, Zhao Y, Yang Z, et al. Inhibition of TGF-beta/Smad signaling by BAMBI blocks differentiation of human mesenchymal stem cells to carcinoma-associated fibroblasts and abolishes their protumor effects. Stem Cells. 2012;30:2810-9.
22. Mi Z, Bhattacharya SD, Kim VM, Guo H, Talbot LJ, Kuo PC. Osteopontin promotes CCL5-mesenchymal stromal cell-mediated breast cancer metastasis. Carcinogenesis. 2011;32:477-87.

23. Schulz KF, Chalmers I, Hayes RJ, Altman DG. Empirical evidence of bias. Dimensions of methodological quality associated with estimates of treatment effects in controlled trials. JAMA. 1995;273:408-12.

24. Hooijmans CR, Geessink FJ, Ritskes-Hoitinga M, Scheffer GJ. A systematic review and meta-analysis of the ability of analgesic drugs to reduce metastasis in experimental cancer models. Pain. 2015;156:1835-44.

25. Vu Q, Xie K, Eckert M, Zhao W, Cramer SC. Meta-analysis of preclinical studies of mesenchymal stromal cells for ischemic stroke. Neurology. 2014:82:1277-86.

26. McIntyre LA, Moher D, Fergusson DA, Sullivan KJ, Mei SH, Lalu M, et al. Efficacy of mesenchymal stromal cell therapy for acute lung injury in preclinical animal models: a systematic review. PLoS ONE. 2016;11:e147170.

27. Chen $Y$, Ling L, Su G, Han M, Fan X, Xun P, et al. Effect of intermittent versus chronic calorie restriction on tumor incidence: a systematic review and meta-analysis of animal studies. Sci Rep. 2016:6:33739.

28. Lv M, Zhu X, Wang H, Wang F, Guan W. Roles of caloric restriction, ketogenic diet and intermittent fasting during initiation, progression and metastasis of cancer in animal models: a systematic review and metaanalysis. PLoS ONE. 2014;9:e115147.

29. Hooijmans CR, Geessink FJ, Ritskes-Hoitinga M, Scheffer GJ. A systematic review of the modifying effect of anaesthetic drugs on metastasis in animal models for cancer. PLOS ONE. 2016:11:e156152.

30. Rolandsson ES, Andersson SA, Skog I, Hansson L, Larsson H, Le Blanc K, et al. MSC from fetal and adult lungs possess lung-specific properties compared to bone marrow-derived MSC. Sci Rep. 2016;6:29160.

31. Lin HR, Heish CW, Liu CH, Muduli S, Li HF, Higuchi A, et al. Purification and differentiation of human adipose-derived stem cells by membrane filtration and membrane migration methods. Sci Rep. 2017:7:40069.

32. Gonzalez ME, Martin EE, Anwar T, Arellano-Garcia C, Medhora N, Lama A, et al. Mesenchymal stem cell-induced DDR2 mediates stromal-breast cancer interactions and metastasis growth. Cell Rep. 2017;18:1215-28.

33. Ljujic B, Milovanovic M, Volarevic V, Murray B, Bugarski D, Przyborski S, et al. Human mesenchymal stem cells creating an immunosuppressive environment and promote breast cancer in mice. Sci Rep. 2013;3:2298.

34. Lacerda L, Debeb BG, Smith D, Larson R, Solley T, Xu W, et al. Mesenchymal stem cells mediate the clinical phenotype of inflammatory breast cancer in a preclinical model. Breast Cancer Res. 2015:17:42.

35. Albarenque SM, Zwacka RM, Mohr A. Both human and mouse mesenchymal stem cells promote breast cancer metastasis. Stem Cell Res. 2011;7:163-71.

36. Sun B, Roh KH, Park JR, Lee SR, Park SB, Jung JW, et al. Therapeutic potential of mesenchymal stromal cells in a mouse breast cancer metastasis model. Cytotherapy. 2009;11(289-298):1-298.

37. Ma F, Chen D, Chen F, Chi Y, Han Z, Feng X, et al. Human umbilical cord mesenchymal stem cells promote breast cancer metastasis by interleukin-8- and interleukin-6-dependent induction of CD44(+)/CD24(-) cells. Cell Transplant. 2015;24:2585-99.

38. Kamat P, Schweizer R, Kaenel P, Salemi S, Calcagni M, Giovanoli P, et al. Human adipose-derived mesenchymal stromal cells may promote breast cancer progression and metastatic spread. Plast Reconstr Surg. 2015;136:76-84.

39. Szebeni GJ, Kriston-Pal E, Blazso P, Katona RL, Novak J, Szabo E, et al. Identification of galectin-1 as a critical factor in function of mouse mesenchymal stromal cell-mediated tumor promotion. PLoS ONE. 2012;7:e41372.

40. Ke CC, Liu RS, Suetsugu A, Kimura H, Ho JH, Lee OK, et al. In vivo fluorescence imaging reveals the promotion of mammary tumorigenesis by mesenchymal stromal cells. PLoS ONE. 2013;8:e69658.

41. Tsukamoto S, Honoki K, Fujii H, Tohma Y, Kido A, Mori T, et al. Mesenchymal stem cells promote tumor engraftment and metastatic colonization in rat osteosarcoma model. Int J Oncol. 2012;40:163-9.

42. Zhang $P$, Dong L, Long $H$, Yang TT, Zhou Y, Fan QY, et al. Homologous mesenchymal stem cells promote the emergence and growth of pulmonary metastases of the rat osteosarcoma cell line UMR-106. Oncol Lett. 2014;8:127-32.

43. Avril $P$, Le Nail LR, Brennan MA, Rosset $P$, De Pinieux $G$, Layrolle $P$, et al. Mesenchymal stem cells increase proliferation but do not change quiescent state of osteosarcoma cells: potential implications according to the tumor resection status. J Bone Oncol. 2016:5:5-14. 
44. Li GC, Ye QH, Xue YH, Sun HJ, Zhou HJ, Ren N, et al. Human mesenchymal stem cells inhibit metastasis of a hepatocellular carcinoma model using the MHCC97-H cell line. Cancer Sci. 2010;101:2546-53.

45. Lin JT, Wang JY, Chen MK, Chen HC, Chang TH, Su BW, et al. Colon cancer mesenchymal stem cells modulate the tumorigenicity of colon cancer through interleukin 6. Exp Cell Res. 2013;319:2216-29.

46. Shinagawa K, Kitadai Y, Tanaka M, Sumida T, Onoyama M, Ohnishi M et al. Stroma-directed imatinib therapy impairs the tumor-promoting effect of bone marrow-derived mesenchymal stem cells in an orthotopic transplantation model of colon cancer. Int J Cancer. 2013;132:813-23.

47. Shinagawa K, Kitadai Y, Tanaka M, Sumida T, Kodama M, Higashi Y, et al. Mesenchymal stem cells enhance growth and metastasis of colon cancer. Int J Cancer. 2010;127:2323-33.

48. Akay I, Oxmann D, Helfenstein A, Mentlein R, Schunke M, Hassenpflug $J$, et al. Tumor risk by tissue engineering: cartilaginous differentiation of mesenchymal stem cells reduces tumor growth. Osteoarthritis Cartilage. 2010;18:389-96.

49. Zhang L, Su XS, Ye JS, Wang YY, Guan Z, Yin YF. Bone marrow mesenchymal stem cells suppress metastatic tumor development in mouse by modulating immune system. Stem Cell Res Ther. 2015:6:45.

50. Yang X, Li Z, Ma Y, Gao J, Liu S, Gao Y, et al. Human umbilical cord mesenchymal stem cells promote carcinoma growth and lymph node metastasis when co-injected with esophageal carcinoma cells in nude mice. Cancer Cell Int. 2014;14:93.

51. Hayes-Jordan A, Wang YX, Walker P, Cox CS. Mesenchymal stromal cell dependent regression of pulmonary metastasis from Ewing's. Front Pediatr. 2014:2:44
52. Xue Z, Wu X, Chen X, Liu Y, Wang X, Wu K, et al. Mesenchymal stem cells promote epithelial to mesenchymal transition and metastasis in gastric cancer though paracrine cues and close physical contact. J Cell Biochem. 2015;116:618-27.

53. Kitayama J, Emoto S, Yamaguchi H, Ishigami H, Watanabe T. CD90+ mesothelial-like cells in peritoneal fluid promote peritoneal metastasis by forming a tumor permissive microenvironment. PLoS ONE. 2014;9:e86516.

54. Wang ML, Pan CM, Chiou SH, Chen WH, Chang HY, Lee OK, et al. Oncostatin m modulates the mesenchymal-epithelial transition of lung adenocarcinoma cells by a mesenchymal stem cell-mediated paracrine effect. Cancer Res. 2012;72:6051-64.

55. Carnet O, Lecomte J, Masset A, Primac I, Durre T, Maertens L, et al. Mesenchymal stem cells shed amphiregulin at the surface of lung carcinoma cells in a juxtacrine manner. Neoplasia. 2015;17:552-63.

56. Keramidas M, de Fraipont F, Karageorgis A, Moisan A, Persoons V, Richard $\mathrm{MJ}$, et al. The dual effect of mesenchymal stem cells on tumour growth and tumour angiogenesis. Stem Cell Res Ther. 2013;4:41.

57. Waghray M, Yalamanchili M, Dziubinski M, Zeinali M, Erkkinen M, Yang H, et al. GM-CSF mediates mesenchymal-epithelial cross-talk in pancreatic cancer. Cancer Discov. 2016;6:886-99.

58. Djouad F, Bony C, Apparailly F, Louis-Plence P, Jorgensen C, Noel D. Earlier onset of syngeneic tumors in the presence of mesenchymal stem cells. Transplantation. 2006:82:1060-6.
Ready to submit your research? Choose BMC and benefit from:

- fast, convenient online submission

- thorough peer review by experienced researchers in your field

- rapid publication on acceptance

- support for research data, including large and complex data types

- gold Open Access which fosters wider collaboration and increased citations

- maximum visibility for your research: over 100M website views per year

At BMC, research is always in progress.

Learn more biomedcentral.com/submissions 